\title{
Biases and Heuristics in Judgment and Decision Making: The Dark Side of Tacit Knowledge
}

\author{
Tayyab Maqsood \\ RMIT University, \\ Victoria, Australia
}

\author{
tayyab.maqsood \\ @rmit.edu.au
}

\author{
Andrew D. Finegan \\ Charles Darwin Uni- \\ versity, NT, Australia
}

\author{
andrew.finegan \\ @cdu.edu.au
}

\author{
Derek H. T. Walker \\ RMIT University, \\ Victoria, Australia
}

\author{
derek.walker \\ @rmit.edu.au
}

\begin{abstract}
The crux of knowledge management theory is to devise different strategies to capture the tacit knowledge of the people in the organization, to make it explicit and to share it throughout the organization. This paper draws from the literature in cognitive psychology and highlights the limitation of the human mind by observing that knowledge is lost out of memory over time. Judgment and gut feelings are usually associated with different forms of biases and heuristics that may influence decision making negatively by altering the context in which the knowledge has been constructed. The paper argues that the timing and context in which tacit knowledge has been shaped is of immense importance when attempting to capture it. It is suggested that, while striving to capture the tacit knowledge of the individuals, it is important to make sure that it is not under the influence of any bias and its context is accurately perceived and preserved. Biased and incomplete knowledge may do more harm than good and should be avoided.
\end{abstract}

Keywords: Knowledge management, tacit knowledge, knowledge construction

\section{Introduction}

The main focus of current knowledge management research is to capture the knowledge that tacitly resides in the employees' heads and to turn it into the explicit form for others to use. Researchers agree that knowledge is a very 'messy' and esoteric concept. Therefore, capturing it is a task fraught with difficulties. But if captured and put into explicit form, tacit knowledge is a driving force behind any sort of innovation, be it new technology, new process or a new technique.

Tacit knowledge by its very nature actually 'emerges' from the people's heads. The various mental processes that shape and construct certain knowledge are very difficult to comprehend. This sort of knowledge is a key behind exercising judgment in human decision-making and employing intuition or 'gut-feeling'. It is seen in experienced managers; because of their tacit knowledge and expertise based on this sort of knowledge, they are able to make better-informed and effective intuitive decisions. However, there is also a probability of these managers making a wrong judg-

Material published as part of this journal, either on-line or in print, is copyrighted by Informing Science. Permission to make digital or paper copy of part or all of these works for personal or classroom use is granted without fee provided that the copies are not made or distributed for profit or commercial advantage AND that copies 1) bear this notice in full and 2) give the full citation on the first page. It is permissible to abstract these works so long as credit is given. To copy in all other cases or to republish or to post on a server or to redistribute to lists requires specific permission from the publisher at Publisher@InformingScience.org ment ending up in wrong decisions.

This paper was inspired by the authors' experience when delivering presentations on knowledge management issues. In several cases members of the audience responded by observing that some tacit knowledge is inaccurate, incorrect or inappropriate. 
Therefore, it is a possibility that the tacit knowledge that we are trying to capture may not be useful. Their objection seems valid when we find out various examples of big judgmental mistakes made by managers that risk and jeopardize a whole project. Through this short paper we acknowledge this fact and endeavor to explain the factors that affect the effectiveness of the tacit knowledge. The paper also examines what can be done to make sure that tacit knowledge stays effective when captured and used in decision-making.

\section{Human Information Processing - Factors Affecting Knowledge Construction}

It is important to know how human information processing occurs as sensing information and utilizing it is a key to further knowledge construction in a human mind. Knowledge is a conclusion drawn from data and information (Stewart, 2000).

\section{Perception and Recognition}

The first element involved in the human information processing that facilitates knowledge construction is perception of the event, and then use of memory to give this perception a recognition. As shown in Figure 1, perception of displays occurs through stimuli generated by various sensory inputs - e.g. vision, audition, chemical senses - i.e. smell and taste.

This system recognizes the information, assembles it, and makes comparisons with previously stored material (knowledge). Knowledge is used, reused and hence gets constructed. Perception is a selective process and certain amounts of information from the outside are selected because not all of the information coming in can be assimilated. Perception is affected by factors such as attitudes, values, motives, stress and a person's background.

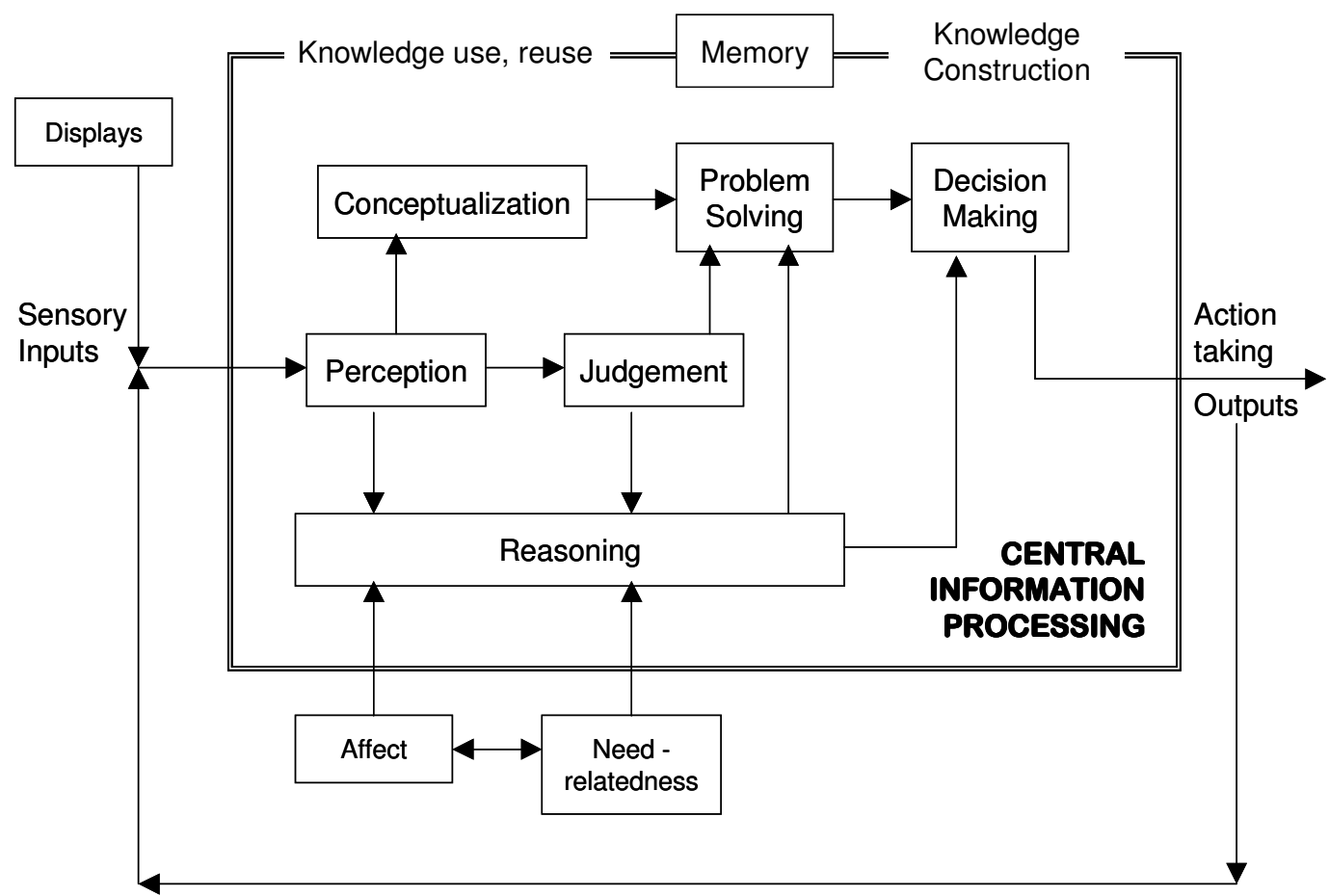

Figure 1: Human Information Processing

(Modified from Kolasa, 1982) 


\section{Cognitive Styles}

van Gigch (1991) defined that cognitive style is "an individual's way of performing perceptual and intellectual activities". It depends upon genetic makeup and environmental factors like education and experience. Managers or thinkers can be classified as systematic, intuitive, receptive and perceptive. The diversity in their education and experience causes differences in their perception and judgment thus rendering their cognitive styles different. Their cognitive structure guides their decision making style whether heuristic or deterministic or a mixture of the two. Cognitive style may also be referred to as high analytical or low analytical.

\section{Heuristics and Biases in Judgment}

'Heuristic' is a term used by psychologists to denote general problem solving procedures that often work in solving everyday problems. It is a rule-of-thumb, a guideline for coming up with a solution (Best, 1989). Skitmore, Stradling, \& Tuohy (1989) mentioned that cognitive heuristics or principles are systematic rules that operate instead of a detailed analysis of the available information thus conserving mental effort. The use of heuristics is very widespread in the construction industry (Flanagan \& Norman, 1993). Although the employment of these heuristics enables the mind to analyze very complex situations, it sometimes leads to severe and systematic errors or biases. Biases have high potential for coming into play when a decision task has a high degree of complexity, high degree of procedural uncertainty and when it is performed under circumstances involving a high degree of stress and time pressure. The susceptibility of human judgment to errors and biases can be attributed to the limitations of human cognitive capacity - the capacity to store, retrieve and process information.

Tversky and Kahnemann (1974) have described three common heuristics: Representative, availability, adjustment and anchoring. The representative heuristic states that the probability that event $\mathrm{A}$ is related to event $\mathrm{B}$ is evaluated by the degree to which A resembles $\mathrm{B}$. The representative heuristic involves search and compare strategies (Chi \& Fan, 1997). The answer to the more familiar problem is adopted as the most likely solution to the present one. The availability heuristic states that instances of large classes are usually recalled better and faster than instances of less frequent classes. Events that are easily computed are perceived as more common and are consequently more available than events whose likelihood is hard to compute (Best, 1989). Adjustment and anchoring refers to the development of beliefs by starting from a particular reference and adjusting it according to the available information. This adjustment process is often faulty. Baron (1998) found that the influence of this heuristic appears to be quite strong and occurs unintentionally and unconsciously.

\section{Functional Fixedness and Mental Set}

Baron (1998) describes 'functional fixedness' as a tendency to use a device or things in a way they have been used in the past and not thinking of creative uses. Mental set is the impact of past experience on present problem solving, specifically the tendency to retain methods that were successful in the past even if better alternatives now exist. It is common on construction sites to deal with repetitively occurring problems the routine way, even if better ways are available.

\section{Mental Models}

Best (1989) describes mental models as internal representations of problems that are formed over a period of time by various experiences of a similar nature. Organisms do more than react to their environment, they learn about it. Learning consists of building representations of the environment that are consulted prior to behavior. These representations are known as cognitive maps. (Tolamn, 1948, 1959; cited in Vandenbosch \& Higgins, 1996). Barlett (1932, cited in Vandenbosch \& Hig- 
gins, 1996) proposes that memory is guided by a mental structure called a schema, an active organization of past reactions, and past experiences. The active nature of a schema is that it is emergent in nature and constantly changing and developing in response to experiences. These mental models determine how environmental stimuli will be interpreted and incorporated or synthesized. Mental models also make knowledge and information processing more efficient by making it unnecessary to construct understanding from the start each time similar stimuli are encountered. They facilitate learning by allowing humans to fill gaps in both information and memory.

\section{Variations in Learning Style and Knowledge Acquisition}

Every human has a unique learning style. Learning depends on the ability of the individual for the acquisition of information and for using it properly and in a timely way for effective decisionmaking. The key to better decision-making lies in obtaining relevant, accurate and timely information and using the cognitive capacity of individual, then translating information into knowledge and decision-making (Wilson, 1995). Learning emerges from the interaction of the stimulus and the mind of the learner and results in the change of the learner's mental model (Vandenbosch \& Higgins, 1996). Ford (1995) observes that individuals differ in ways in which they can and do structure information in learning and problem solving contexts. Norman (1982, cited in Vandenbosch and Higgins, 1996) identifies three modes of learning: 'Accretion' is the addition of new knowledge to existing schemata. This is the most common mode of learning. 'Structuring' is the formation of new schemata. The existing models are not sufficient to handle the problem faced so new models have to be developed. 'Tuning' is the fine adjustment of knowledge to a task. Adjustment is needed because the existing schemata are too general or because they are mismatched to the particular use that is required of them.

Long-term memory consists of both declarative and procedural knowledge. Best (1989) classifies declarative knowledge as 'knowledge that' and procedural as 'knowledge how'. These forms of knowledge require different means of learning. Declarative knowledge is flexible and can often be reorganized to suit our purposes. Procedural knowledge is not as flexible. The organization of procedural knowledge is not known to us, nor is procedural knowledge usually very describable. It is easier to show than to tell and refers to the knowledge underlying skilful actions. Reuber (1997) describes procedural knowledge as an expertise, which comes through experience.

\section{Tacit Knowledge Construction - A Practical Example}

The learning process of a new graduate joining a construction site starts when s/he begins working as a site engineer. Engineering education doesn't contribute greatly to the knowledge required to handle construction tasks (Warszawski, 1984), so the site engineer learns everything from the site process. While passing time in this trade s/he will go through various mental model building and maintenance stages and develop expertise. The development of the expertise is different for various site managers even if they have spent the same amount of time (Baird, 1989). This shows that expertise is not only a matter of spending time in a certain trade. The number of years passed is only a crude measure of gauging expertise and is used to place a sort of confidence on the person. However, the person who has passed adequate time on site process but not able to develop adequate expertise will not perform as effectively as the person who has developed enough expertise. There are no direct measures of criteria to determine expertise. Indirectly it can be gauged by observing the quality of performance shown in site processes. This leads to the point that the tacit knowledge elicited by these site managers would be of different nature and quality even if they have gone through similar work routines. 


\section{The Importance of Context}

Fernie, Green, Weller, \& Newcombe, (2003) discusses the importance of context when comparing organizations with a view of utilizing knowledge gained in one sector and applying to other sectors. They emphasized that while doing so - industry context, which involves political, economic, social, technological, legal, environmental and structural factors inherent in each sector must not be overlooked. Knowledge needs to be extracted from one context and be converted and adapted to another context. Thomson, Warhurst, \& Callaghan, (2001) consider this process as recontextualization. Sometimes recontextualization alters the knowledge to such an extent that represents a new knowledge (Fernie et al., 2003).

Every task in a construction process has a certain context associated with it in which it is executed and completed. The constructed knowledge that occurs is deeply dependent on this context. This context provides the boundary conditions for the constructed knowledge, and it is considered valid provided it satisfies the limiting boundary conditions (i.e. context). Ideally it means that the knowledge can be applied repetitively to the situations if the context under which it is constructed remains unaltered. Practically, it is very hard to find a situation where the context is exact replica of some previous event. Especially in a construction process, context is always varying. This difference in contexts is one of the reasons that mislead construction managers into wrong decisionmaking using tacit knowledge. The basis upon which they are making the decisions has shaped itself under a different context. If managers are aware of the context in which they gain a certain experience, and keep that context in mind to alter their decision-making processes to reflect the changes in the context, they are in a position to minimize the biases and hence having great chance of successful decision-making.

The same holds true while attempting to capture tacit knowledge. Capturing the tacit knowledge without capturing the context in which it was constructed may seriously jeopardize its effectiveness. Knowledge managers need to be fully aware of this aspect of knowledge elicitation. When the captured knowledge is to be further shared and used, related context must also be communicated. It becomes necessary to recontextualize it to reflect the changes in the context to use it efficiently.

\section{Importance of Timing}

The human mind has a lot of limitations and one of the severe limitations is that the knowledge starts to lapse from memory or become faded and confused over time. Where construction tasks are heavily repetitive, this limitation may not be a problem. However, for unique and innovative tasks, delay in timing to capture a constructed knowledge may pose problems in the validity and effectiveness of the knowledge captured. Aligned with the concept of knowledge management is a concept of project histories or project databases that may be maintained as a part of knowledge management initiative in an organization and contains knowledge generated in various projects to be used on future projects.

Schindler and Eppler (2003) have reviewed and discussed various ways to harvest project knowledge. They identified two ways of capturing project knowledge. Process-based methods (Project Reviews/Audit) gather lessons learned from the concluded projects and documentation-based methods (Micro Article, Learning Histories, RECALL) to learn from project experiences on an on-going basis. Documentation based methods are superior to the process based methods because they offer continuous project learning through regular reviews. The events are more recent and the subsequent learning can be recalled more easily (Schindler \& Eppler, 2003). 


\section{Conclusion}

In this paper we have addressed the query that is often encountered when presenting on knowledge management issues, especially tacit knowledge. This is the observation that not every bit of tacit knowledge is necessarily 'correct' and there are various factors that influence the quality of knowledge being captured. To identify these factors we have reviewed the literature in cognitive psychology. Human information processing is a complex phenomenon and varies from person to person. Processing certain information means constructing particular sorts of knowledge. Such construction of knowledge is dependent on a number of factors like perception and recognition, cognitive styles, heuristics and biases in judgment, functional fixedness and mental set, mental models etc. These factors generate various learning modes, reflected in the way humans acquire knowledge and develop expertise.

We have placed great importance on the context in which certain knowledge shapes itself. It is important to capture the context together with the knowledge so that user may recontextualize the knowledge depending on the current context for effective use. Also, timing is important in the capture of certain knowledge. Early capturing guarantees the effectiveness and usefulness of the knowledge. Finally, documentation-based methods for capturing project knowledge - ensuring regular on-going continuous knowledge capture - are preferred over process-based methods.

\section{References}

Baird, B.F. (1989). Managerial decisions under uncertainty: An introduction to the analysis of decision making. New York: John Wiley \& Sons.

Baron, R.A. (1998). Psychology (4 ${ }^{\text {th }}$ ed.). U.S.A.: Allyn and Bacon.

Bartlett, F.C. (1932).) Remembering: A study in experimental and social psychology. London: Cambridge University Press. Cited in Vandenbosch \& Higgins, (1996).

Best, J.B. (1989). Cognitive psychology. U.S.A.: West Publishing.

Chi, T. \& Fan, D. (1997). Cognitive limitations and investment 'myopia'. Decision Sciences, 28 (1), 27-45.

Fernie S., Green, S.D., Weller, S.J. \& Newcombe, R., (2003). Knowledge sharing: Context, confusion and controversy. International Journal of Project Management, 21, (3), 177-186.

Flanagan, R. \& Norman, G. (1993). Risk management and construction. Black Well, Great Britain: Scientific Publications.

Ford, N. \& Ford, R. (1983). Towards a cognitive theory of information accessing: An empirical study. Information Processing and Management, 29 (5), 569-585.

Kolasa, B.J. (1982). Introduction to behavioral sciences for business (3rd ed.). India: Wiley Eastern Limited.

Norman, D.A. (1982). Learning and memory. San Francisco: W. H. Freeman. Cited in Vandenbosch \& Higgins, (1996)

Reuber, R. (1997). Management experience and management expertise. Decision Support Systems, 21, (2), 51-60.

Schindler, M. \& Eppler, M.J. (2003). Harvesting project knowledge: A review of project learning methods and success factors. International Journal of Project Management, 21, (3), 219-228.

Skitmore, R.M., Stradling, S.G. \& Tuohy, A.P. (1989). Project management under uncertainty. Construction Management and Economics, 7, 103-113.

Stewart, T.A. (2000). Intellectual capital - The new wealth of organizations. London: Nicholas Brealey. 
Thompson P., Warhurst C. \& Callaghan G. (2001). Ignorant theory and knowledgeable workers: Interrogating the connections between knowledge, skills and services. Journal of Management Studies, Special Issue: Knowledge Management: Concepts and Controversies, 38 (7), 923-942.

Tolman, E.C. (1948). Cognitive maps in rats and men. Psychological Review, 55, 189-208. Cited in Vandenbosch \& Higgins, (1996).

Tversky, A. \& Kahnemann, D. (1974). Judgment under uncertainty: Heuristic and biases. Science, 85, 1124-1131.

van Gigch, J.P. (1991). System design modeling and meta modeling. New York: Plenum Press.

Vandenbosch, B, \& Higgins, C. (1996). Information acquisition and mental models: An investigation into the relationship between behavior and learning. Information System Research, 7, (2), 198-214.

Warszawski, A. (1984). Construction management program. Journal of Construction Engineering and Management, 110 (3), 297-310.

Wilson, T. (1995). Modeling the information user: The wider perspective. INFOTECH '95 Conference, Kuala Lumpur, Malaysia, November, 1995.

\section{Biographies}

Tayyab Maqsood is currently pursuing his Doctoral Degree in RMIT University sponsored by CRC for Construction Innovation and is conducting a research on the topic of Knowledge Management, Learning and Innovation in the Australian Construction Industry. Tayyab is a Civil Engineer with Masters of Engineering Degree in Construction Engineering and Management from Asian Institute of Technology, Bangkok, Thailand. He has worked in Pakistan, Thailand, UK and Hong Kong in various capacities as lecturer, project engineer and research associate over last 9 years. His research interests include Project Management, Risk Management, Partnering, Knowledge Management, Information Communication Technologies (ICT) and Supply Chain Management.

Andrew D. Finegan is Senior Lecturer in e-Business in the School of Information Technology at Charles Darwin University. Andrew's research interests encompass the areas of systems thinking, project management, and the management of innovation. He obtained a Master of Engineering Degree in Systems Engineering in 1990, and a PhD in 2001, both from RMIT University.

Derek HWalker is Professor of Project Management at the Faculty of Business, RMIT University. He worked in various project management roles in the UK, Canada, and Australia for 16 years before commencing his academic career in 1986. He obtained a Master of Science from the University of Aston (Birmingham) in 1978, and a PhD in 1995 from RMIT University (Melbourne). He has written over 90 peer reviewed papers and book chapters. His research interests centre on innovation diffusion of information and communication technologies, knowledge management, project management and project procurement systems. He is also the Program Director of the Doctor of Project Management (DPM) program. 